\title{
Influence of Bioaugmentation Strategy of Activated Sludge on the Co-Treatment of Reject Water and Municipal Wastewater at a Decreasing Temperature
}

\author{
Aleksandra Szaja', Joanna Szulżyk-Cieplak ${ }^{2 *}$ \\ 1 Lublin University of Technology, Faculty of Environmental Engineering, Nadbystrzycka 40B, 20-618 Lublin, \\ Poland \\ 2 Lublin University of Technology, Faculty of Fundamentals of Technology, Nadbystrzycka 38, 20-618 Lublin, \\ Poland \\ * Corresponding author's e-mail: j.szulzyk-cieplak@pollub.pl
}

\begin{abstract}
In the present study, the influence of bioaugmentation strategy on the co-treatment of $13 \% \mathrm{v} / \mathrm{v}$ reject water and municipal wastewater at a decreasing temperature was evaluated. The experiment was performed in two identical laboratory sequencing batch reactors with the active volume of $8 \mathrm{~L}$. Each one was operated using a 12-hour cycle at sludge retention time of $3 \mathrm{~d}$. The SBR A was bioaugmented with a mixture of wild-living bacteria and Archaea in a dose $0.25 \mathrm{ml}$. In turn, the comparative reactor (SBR B) was non-bioaugmented, the Archaea product was replaced with an equal volume of dechlorinated tap water. The experiment was divided into 3 phases, each with a different temperature range $\left(20,15\right.$ and $\left.10^{\circ} \mathrm{C}\right)$. The temperature reduction did not adversely affect the process performance in the bioaugmented and non-bioaugmented system. Significant removal efficiencies were achieved in both SBRs. The major differences were observed for the COD content in the bioaugmented SBR at a temperature of $10^{\circ} \mathrm{C}$. In this case, statistically lower concentrations in the effluent were observed in the bioaugmented system than in the non-bioaugmented one. Additionally, at a temperature of $10^{\circ} \mathrm{C}$, an improved process performance was observed in the Archaea presence, but the differences were of no statistical significance.
\end{abstract}

Keywords: bioaugmentation, reject water, SBR, decreasing temperature, Archaea

\section{INTRODUCTION}

Over the last years, several technologies for biological wastewater treatment have been have been developed. However, one of the most commonly applied systems is the activated sludge process [Babko et al., 2016; Guo et al., 2019]. Therein, pollutants are biodegraded by the microorganisms suspended in the activated sludge under the aerobic, but also anoxic and anaerobic conditions [Gernaey, 2008; Fyda et. al 2015]. Currently, one of the main concerns of many wastewater treatment plants (WWTPs) is high energy demand [Masłoń 2017; Drewnowski et al., 2019] and presence of new and previous absent pollutants (emerging pollutants) e.g. synthetic organic compounds [Deblonde et al., 2011], pharmaceuticals [Katsou et al, 2016; Benedetti et al., 2020], disinfectants and hormones [Dudziak and Burdzik-Niemiec, 2017; Zhou et al., 2019]. Another aspect is the stricter legislation concerning the effluent quality [EU Water Framework Directive 2015/495]. These problems have been related with the increasing operational costs, as well as the necessity of process improvement [Piechna and Żubrowska-Sudoł, 2017; Szezląg et al., 2018; Guo et al., 2019]. A rapid detection and response to the process inhibition have also been a key factor in effective WWTP operation [Guz et al., 2015; Łagód et al., 2018] Hence, the innovative strategies for the activated sludge optimization have constantly been sought [Czarnota et al., 2019; Roots et al., 2020]. Moreover, the approaches that could be easily implemented at 
WWTPs without the necessity to reconstruct the existing objects seem to be particularly beneficial. One of the possible tools to overcome these difficulties is bioaugmentation [van Limbergen et al., 1998; Bathe et al., 2009]. It involves the introduction of specific competent strains or consortia of microorganisms to a contaminated environment or bioreactors to enhance the removal of undesired compounds or improve the process performance [van Limbergen et al., 1998, Grabas et al., 2016]. This method has been widely applied to the activated sludge systems to achieve stable treatment performance in the presence of such process inhibitors as phenolic compounds, surfactants, herbicides, heavy metals, sulfides, and ammonia [Semrany et al., 2012; Polus and Anielak, 2017]. Various implementations have concerned the treatment of the industrial wastewater from, e.g. refineries [Ma et al., 2009] paper [Zheng et al., 2013], steel [Park et al., 2008] and tobacco [Wang et al., 2010] industries. Another application of this strategy involved the improvement of the biodegradation of toxic organic compounds such as endocrine agents, pharmaceuticals, and personal care products [Boonnorat et al., 2018]. The potential of this method has also been demonstrated to accelerate the start-up period of bioreactors [Gou et al., 2010; Cui et al., 2014]. Bioaugmentation has also been applied as a tool to protect the structure of microbial community against various stress conditions such as low temperature [Head and Oleszkiewicz, 2004], high nitrate load [Tan et al., 2016], reduced oxidation and feeding disturbances [Szaja et al., 2018].

Another serious issue that may disrupt the operation of the biological reactors at many WWTPs, is the contribution of significantly contained wastewater from sewage sludge processing to the main flow [Hu et al., 2017; Drewnowski et al., 2019]. This side-stream, called reject water, provides $10-50 \%$ and $10-80 \%$ of nitrogen and phosphorus load, respectively [Ren et al., 2015]. Currently, it is recommended that this wastewater should be pre-treated before recycling and supplying the main influent [Marttinen et al., 2004]. However, many WWTPs still cannot afford the construction of separate and advanced facilities for a relatively small flow rate of the reject water. Under the Polish conditions, low temperature is an additional and frequently appearing factor that can affect the biomass activity as well as the physiochemical properties of the mixed liquor in the activated sludge systems. Moreover, the adaptation of the microorganisms in the biological reactors to abrupt temperature variations is significantly limited [Mąkinia et al., 2005; Shahzad et al., 2015]. It should be noticed that the nitrifying bacteria are particularly very sensitive to low temperature. A sudden decrease in temperature resulted in the low efficiency of the nitrification process that is crucial and frequently a rate-limiting step in the nitrogen removal [Hwang and Oleszkiewicz, 2007; Zhang et al., 2009]. Below $15^{\circ} \mathrm{C}$, such negative changes as reduced grow rate of nitrifiers, decreased substrate utilization rate, deterioration of the settling ability of activated sludge are noted [Cui et al., 2014]. Interestingly, the recent studies have confirmed the possibility of applying the bioaugmentation strategy to the activated sludge systems in order to enhance the nitrification capacity at low temperature [Head and Oleszkiewicz, 2004; Cui et al., 2014; Figdore et al., 2018].

In the present study, the influence of the bioaugmentation strategy on the co-treatment of reject water and municipal wastewater in SBR (sequencing batch reactor) at a decreasing temperature was evaluated. A mixture of wild-living bacteria and Archaea from Yellowstone National Park (ArcheaSolutions Inc.) was applied. It should be noted that the studies in this area have not been performed so far.

\section{MATERIALS AND METHODS}

\section{Laboratory installation and pperational set-up}

The experiments were performed in laboratory SBRs with an active volume of $8 \mathrm{~L}$ (Fig. 1). Each of them was equipped with a mechanical stirrer, an air membrane diffuser and control unit. In order to maintain the adopted temperature, the reactors were kept in water bath.

Each SBR cycle consisted of the following phases: feed (30 min), reaction (mixing $120 \mathrm{~min}$ and aeration $420 \mathrm{~min}$ ), sedimentation (90 min) and effluent (30 min). Additionally, the operational phase which lasted $30 \mathrm{~min}$ for excessive sludge removal and wastewater sampling was distinguished. In the conducted studies, each SBR was operated using a 12-hour cycle. 


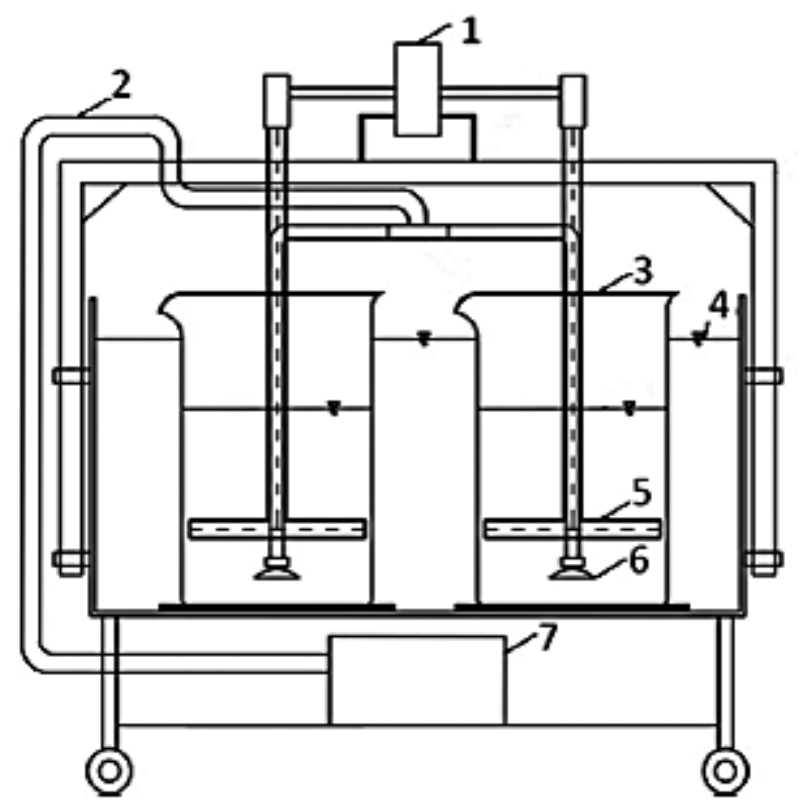

Figure 1 The laboratory installation used in the experiment [Szaja et al., 2018]:

1 - electric motor driving the mixing system; 2 - distribution pipes for pressured air; 3 - SBR-type bioreactor; 4 - water bath with stabilized temperature; 5 - low-speed blade stirrer; 6 - membrane diffuser; 7 - membrane supercharger supplying the aeration system with pressured air

The experiment was divided into three phases with different temperature, each lasted 13 days. In the first one, the temperature was maintained at $20^{\circ} \mathrm{C}$. After this stage, the temperature was reduced to $15^{\circ} \mathrm{C}$ and finally the temperature was estimated at $10^{\circ} \mathrm{C}$.

In the present study, the SBR A was bioaugmented with an Archaea domain microorganism, while the SBR B was non-bioaugmented (control one). The dose of $0.25 \mathrm{~L}$ of bioaugmented product was added to the SBR A. In the control reactor (SBR B) the bioaugmentation product was replaced with an equal volume of dechlorinated tap water. A detailed operational set-up is presented in Table 1 and Figure 2. Both reactors were supplied with the wastewater that contained a constant volume of reject water $(13 \% \mathrm{v} / \mathrm{v})$. The effectiveness of the bioaugmentation strategy was examined based on the removal efficiencies, process stability and effluent concentrations.

\section{Material characteristic}

All samples used in the experiment were collected from the mechanical-biological Lublin WWTP with the daily flow of $65000 \mathrm{~m}^{3} / \mathrm{d}$. An inoculum for the laboratory reactors was obtained from the aeration tank involving a modified Bardenpho method [Guz et al., 2015]. The characteristic of seeding sludge was as follows: sludge retention time (SRT) of 14.9 days, mixed liquor suspended solids (MLSS) $3.21 \mathrm{~g}$ $\mathrm{dm}^{-3}$ and mixed liquor volatile suspended solids (MLVSS) $2.45 \mathrm{~g} \mathrm{dm}^{-3}$. The food to microorganism ratio ( $\mathrm{F} / \mathrm{M}$ ratio) was $0.12 \mathrm{gBOD}_{5} /$ gMLVSS $\cdot d$ and the sludge volume index (SVI) $236 \mathrm{~mL} \mathrm{~g}^{-1}$. The adaptation of the biomass in the SBRs was achieved after $20 \mathrm{~d}$.

The wastewater was obtained from the primary sedimentation tank effluent. In turn, the reject waste was taken from the dewatering belt press.

Table 1. Operational set-up in experiment

\begin{tabular}{|c|c|c|c|}
\hline Run & Feedstock composition & Component volume & Operational conditions \\
\hline \multirow{3}{*}{ SBR A } & wastewater & $2.5 \mathrm{~L}$ & \\
& reject water & $0.4 \mathrm{~L}$ & oxygen concentration -2.0 \\
& bioaugmentation product & $0.25 \mathrm{~L}$ & $\mathrm{mgO}_{2} / \mathrm{L}$ \\
& wastewater & $2.5 \mathrm{~L}$ & $\mathrm{SRT}=3 \mathrm{~d}$ \\
SBR B & reject water & $0.4 \mathrm{~L}$ & \\
& dechlorinated tap water & $0.25 \mathrm{~L}$ & \\
\hline
\end{tabular}




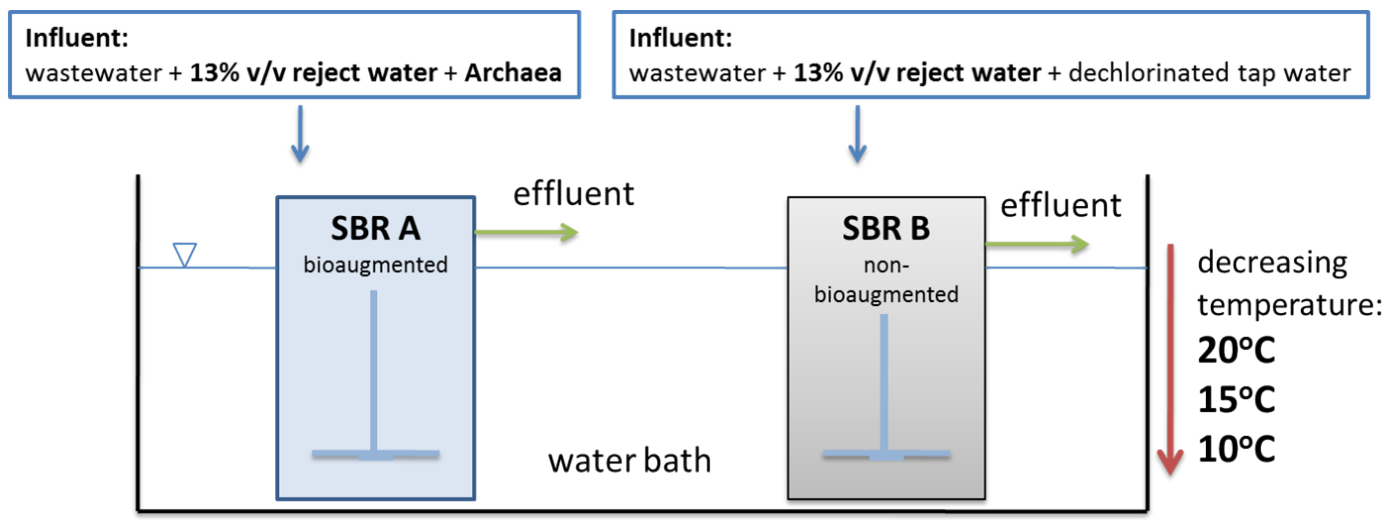

Figure 2. The scheme of conception and operational conditions in the experiment

These samples were taken twice a week; then, they were transported to the laboratory and stored at $4^{\circ} \mathrm{C}$ in a refrigerator. Before supplying the SBR, the wastewater samples were kept for some time in the indoor air to reach $20^{\circ} \mathrm{C}$ and then were homogenized in the adopted proportions using a low-speed mixer.

The wild-living bacteria and Archaea from Yellowstone National Park, USA were used for bioaugmentation (ArcheaSolutions Inc.). The bioaugmentation product was added to SBRs as a solution prepared from a solid substrate. The generation of liquid occurred in a specially constructed preparation device working in a continuous mode. The detailed procedure of the solution preparation was described in the previous works [Lebiocka et al., 2018; Szaja et al., 2018]. The characteristics of both wastewater types and the Archaea product used in the experiments are presented in Table 2.

\section{Analytical methods and statistical analysis}

The wastewater samples were analyzed after delivery to the laboratory. In turn, the characteristics of inoculum for SBRs and bioaugmentation product were determined once.
The following parameters were measured: the total chemical oxygen demand (COD), total nitrogen $(\mathrm{TN})$, ammonia nitrogen $\left(\mathrm{NH}_{4}^{+}-\mathrm{N}\right)$, nitrate nitrogen $\left(\mathrm{NO}_{3}^{-}-\mathrm{N}\right)$ and nitrite nitrogen $\left(\mathrm{NO}_{2}^{-}-\mathrm{N}\right)$. Additionally, the $\mathrm{pH}$ level, turbidity and TSS were controlled. Most experimental analyses were performed spectrophotometrically (Hach Lange UV-VIS DR 5000) using the Hach analytical methods (test cuvettes). The $\mathrm{pH}$ and DO values were monitored by means of a HQ 40D Hach-Lange multimeter (Hach, Loveland, CO, USA). Total and volatile solids were determined according to the Standard Methods for the Examination of Water and Wastewater (APHA, 2005). The results presented in tables and figures are the average values. The differences were assumed to be statistically significant at $\mathrm{p}<0.05$.

\section{RESULTS AND DISCUSSION}

As shown in table 2, the reject water used in the present study is characterized by lower concentrations than those presented in the literature [Ren et al., 2015; Guo et al., 2010; Dosta et al. 2007]. The most significant differences were noted for the COD concentration; typically, this

Table 2 The characteristic of substrates used in the experiment (the mean value and standard deviation are given)

\begin{tabular}{|c|c|c|c|c|}
\hline Parameter & Unit & Reject water & Wastewater & Archaea liquor* \\
\hline COD & \multirow{5}{*}{$\mathrm{mg} / \mathrm{L}$} & $75.33 \pm 10.42$ & $620.00 \pm 1.20$ & $22 \pm 1.0$ \\
\hline TN & & - & - & $75 \pm 1.0$ \\
\hline $\mathrm{NO}_{3}^{-}-\mathrm{N}$ & & $0.81 \pm 0.23$ & $0.92 \pm 0.01$ & - \\
\hline $\mathrm{NO}_{2}^{-}-\mathrm{N}$ & & $0.20 \pm 0.11$ & $0.23 \pm 0.004$ & - \\
\hline $\mathrm{NH}_{4}^{+}-\mathrm{N}$ & & $155.51 \pm 24.98$ & $6.02 \pm 0.04$ & $0.4 \pm 0.02$ \\
\hline $\mathrm{pH}$ & & $7.9-8.05$ & $7.56-7.9$ & 7.16 \\
\hline TSS & $\mathrm{mg} / \mathrm{L}$ & $20.33 \pm 1.21$ & $270.67 \pm 1.52$ & $6 \pm 1.0$ \\
\hline turbidity & NTU & $14.79 \pm 4.14$ & $125.67 \pm 0.57$ & - \\
\hline
\end{tabular}

* [Szaja et al., 2018] 
parameter varied between 1500-2000 mg/L [Dosta et al. 2007]. Moreover, the ammonia nitrogen content was also reduced as compared to the reported results. This wastewater could contain even 750 to $1500 \mathrm{mg} / \mathrm{L}$ [Berends et al., 2005; Perez et al., 2007]. According to Guo et al. [2010], the concentration of $\mathrm{NO}_{2}^{-}-\mathrm{N}$ did not exceed the value of $0.05 \mathrm{mg} / \mathrm{L}$, in the present study, the highest concentrations were recorded. The observed differences might result from the influent wastewater composition as well as the technology adopted for the sewage sludge treatment. Moreover, the reject water was taken from a full-scale WWTP during the summer period, when carbon removal as well as nitrification, denitrification and biological dephosphatation processes occurs more intensively. The characteristics of effluents from the bioaugmented and non-bioaugmented reactor are presented in Figure 3 and 4.

In the first phase of the experiment, the temperature was maintained at $20^{\circ} \mathrm{C}$. Considering the removal efficiency of the analyzed parameters, significant COD, ammonia nitrogen and TSS reductions were achieved for both SBRs. Importantly, more than $99 \%$ of removal efficiency was observed for ammonia nitrogen in both the bioaugmented and non-bioaugmented system. In SBR A, the average concentration was $0.44 \pm 0.03$, while in SBR B, it reached $0.41 \pm 0.02 \mathrm{mg} / \mathrm{L}$. Moreover, the COD removal efficiency reached about $94 \%$ for both SBRs. The average concentration in the effluent was $25.4 \pm 1.7$ and $26.4 \pm 2.1 \mathrm{mg} / \mathrm{l}$ in SBR
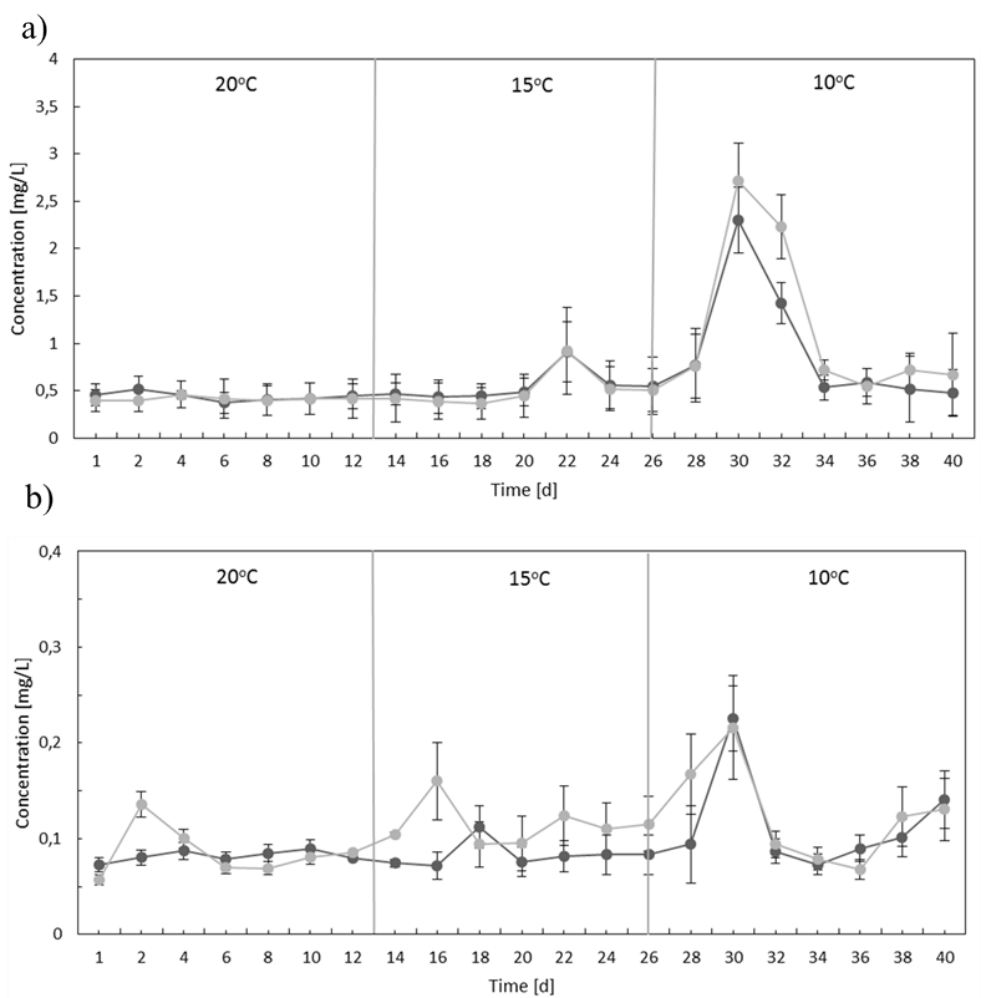

c)

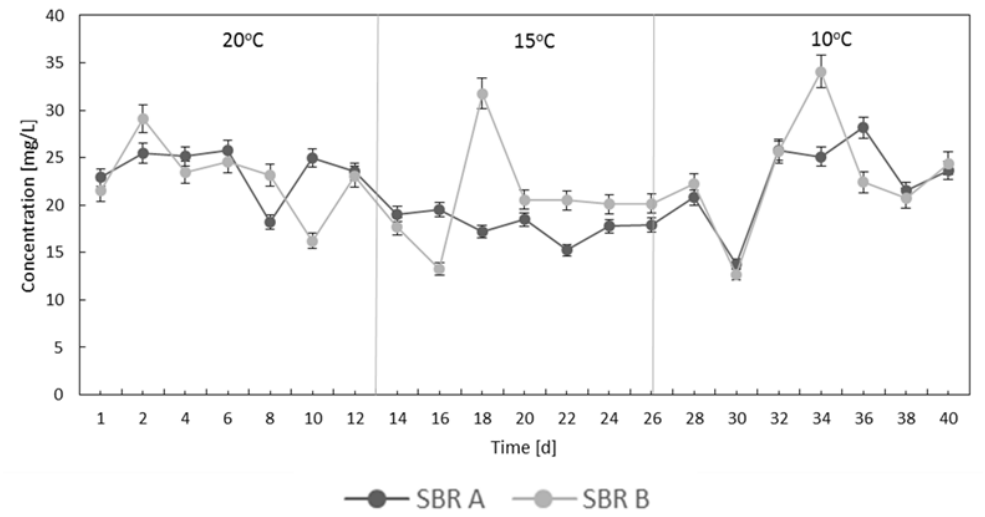

Figure 3. The concentrations of a) ammonia nitrogen b) nitrite nitrogen c) nitrate nitrogen in the effluent of SBR A and SBR B (average data are presented and standard deviations are given) 
a)

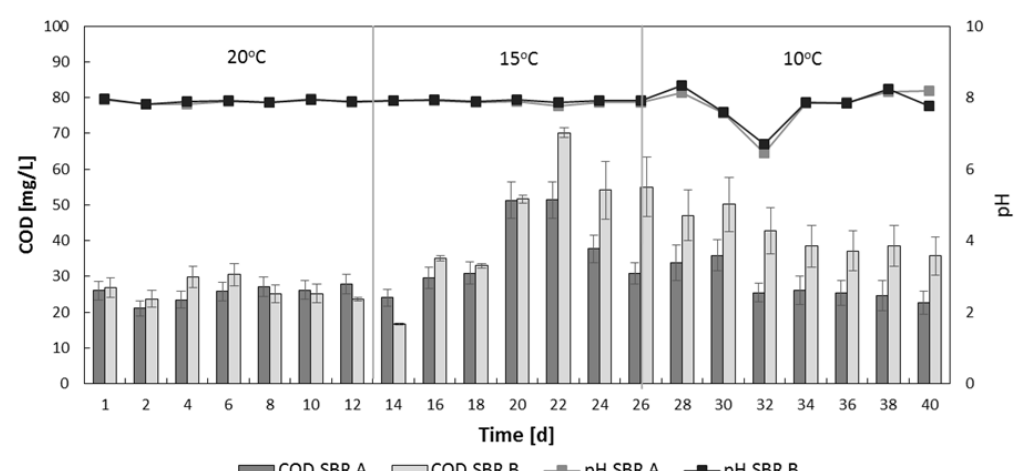

b)

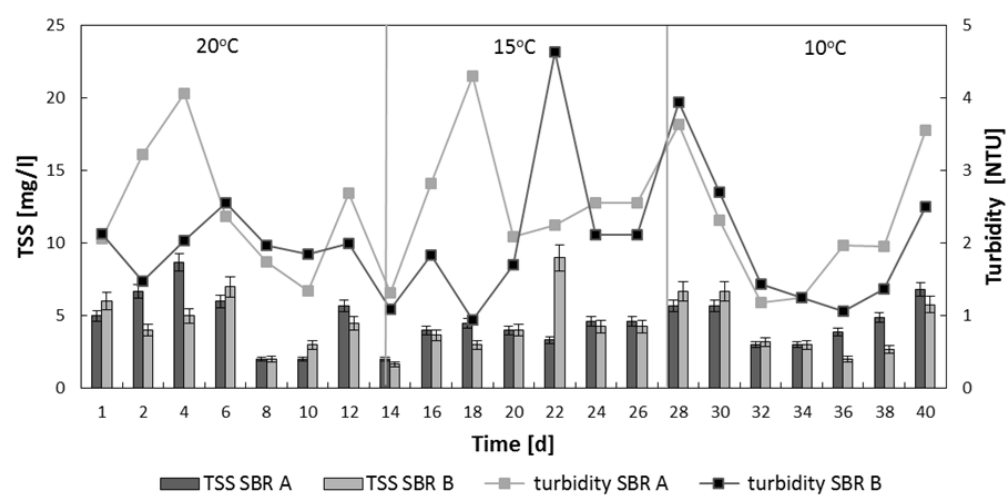

Figure 4. The characteristics of effluent wastewater in SBR A and SBR B a) pH value and COD concentration b) turbidity value and TSS concentration (average data are presented and standard deviations are given)

A and SBR B, respectively. Analogously to COD and $\mathrm{NH}_{4}^{+}-\mathrm{N}$, the TSS removal was approx. 97\% in both SBRs. However, the highest concentration was found in the bioaugmented system; therein the average value was $5.1 \pm 1.8 \mathrm{mg} / \mathrm{L}$. In turn, in the control reactor it was $4.5 \pm 1.2 \mathrm{mg} / \mathrm{L}$. In this stage, the nitrite nitrogen content was reduced by $60 \%$ and $55 \%$ in the bioaugmented and nonbioaugmented SBR, respectively. Therein, the average values in the effluent were $0.08 \pm 0.004$ and $0.09 \pm 0.02$ in SBR A and SBR B, respectively. The different tendency was observed for nitrate nitrogen. In this case, due to the nitrification process, its concentrations in the effluent increased. The average values of $23.7 \pm 1.9$ and $23 \pm 2.8 \mathrm{mg} / \mathrm{L}$ were found in SBR A and SBR B, respectively. It is worth mentioning that the $\mathrm{pH}$ value in both SBRs remained at a favorable level of $\mathrm{pH}$ 7.9. Considering the previously mentioned parameters, the observed differences between the bioaugmented and control reactors were no of statistical significance. The major change between the bioaugmented and non-bioaugmented system was noted with regard to turbidity. This parameter reached 2.5 \pm 0.2 and $2.0 \pm 0.24$ in SBR A and SBR B, respectively. Therein, the statistically significant increased value was found in the bioaugmented reactor.

After 13 days of the SBRs operation, the temperature was decreased to $15^{\circ} \mathrm{C}$. In this phase, the significant removal efficiencies with regard to COD, ammonia nitrogen and TSS were found in both SBRs. However, as compared to the first phase, the decreasing tendency was observed for COD. In this case, the removal efficiencies were 92.6 and $90.8 \%$ in SBR A and SBR B, respectively. In the bioaugmented system, the lower COD concentration was found as compared to the non-bioaugmented one, but the observed differences were of no statistical significance. The average values were $36.5 \pm 8$ and $45.1 \pm 13 \mathrm{mg} / \mathrm{L}$ in SBR A and SBR B, respectively. As previously, more than $99 \%$ removal efficiency for ammonia nitrogen was observed in both reactors. Thus, as compared to the first phase, increased concentrations were observed. The average values were $0.55 \pm 0.12$ and $0.51 \pm 0.14 \mathrm{mg} / \mathrm{L}$ in SBR A and SBR B, respectively. In this case, the observed differences between the bioaugmented and nonbioaugmented system were statistically significant. Similarly to the first period, the TSS removal efficiency reached about $97 \%$ in both SBRs with 
average values of $4.6 \pm 1.8$ and $4.27 \pm 1.7 \mathrm{mg} / \mathrm{L}$ in the bioaugmented and non-bioaugmented system, respectively. In comparison to the previous stage, the unchanged tendency was observed for nitrite nitrogen removal efficiency. Despite the influent concentration comparable to the first phase, an increased value of $0.11 \pm 0.02 \mathrm{mg} / \mathrm{L}$ was noticed in the control reactor. For nitrate nitrogen, the average concentrations of $17.89 \pm 1.03$ and $20.16 \pm 4.87 \mathrm{mg} / \mathrm{L}$ in SBR A and SBR B were found, respectively. As previously, the $\mathrm{pH}$ value in both reactors was maintained at a stable level of $\mathrm{pH}$ 7.9. Moreover, in the bioaugmented SBR, the turbidity level was increased as compared to the non-bioaugmented one, but the difference was not statistically significant. The average values of $2.56 \pm 0.67$ and $2.11 \pm 0.9$ NTU were observed in SBR A and SBR B, respectively.

Decreasing the temperature by another $5^{\circ} \mathrm{C}$ has not affected the analyzed removal efficiencies significantly, as compared to the previous phases. However, regarding $\mathrm{COD}, \mathrm{NO}_{2}^{-}-\mathrm{N}$ and $\mathrm{NO}_{3}^{-}-\mathrm{N}$, lower concentrations were observed in the bioaugmented SBR than in the non-bioaugmented one (Fig. 3). It should be mentioned that the observed differences were of no statistical significance. However, at a temperature of $10^{\circ} \mathrm{C}$, the monitored concentrations in the effluent were characterized by a major variance, increased standard deviation values were noticed as compared to the previous phases. As shown in Fig. 3 and 4, increases in the effluent concentrations of all analyzed parameters were noticed at the initial stage of this phase. After 10 days of the adaptation of microorganisms to new adverse conditions, the obtained results were comparable to the previous phases. Analogous observations were made in the study performed by Hwang and Oleszkiewicz [2007]. They indicated that prolonged adaptation time of the nitrifiers in the bioaugmented system to a low temperature could neglect the negative effect of this indicator. It should be mentioned that significant removal efficiencies have still been found in both systems in comparison to the prior stages. The reduction of the COD concentration was established at $95 \%$ and $90 \%$ in SBR A and SBR B, respectively. Notably, a significant removal efficiency of approx. $98 \%$ was also maintained for $\mathrm{NH}_{4}^{+}$-N. As in the previous case, a significant reduction of $97 \%$ was achieved in relation to the TSS, in both SBRs. However, regarding the COD concentration in the effluent, statistically lower results were observed in the bioaugmented system than in the non- bioaugmented one. In this phase, the average concentrations were $27.7 \pm 3.7$ and $41.4 \pm 4.0 \mathrm{mg} / \mathrm{L}$ in SBR A and SBR B, respectively. Other average concentrations were at a comparable level in both reactors. In the bioaugmented system, the following values were obtained: $1.37 \pm 1.09,0.12 \pm 0.04$ and $22.4 \pm 3.4 \mathrm{mg} / \mathrm{L}$ for $\mathrm{NH}_{4}^{+}-\mathrm{N}, \mathrm{NO}_{2}^{-}-\mathrm{N}$ and $\mathrm{NO}_{3}^{-}-\mathrm{N}$, respectively. In turn, the values in the non-bioaugmented reactor were: $1.05 \pm 0.48,0.13 \pm 0.04$ and $22.9 \pm 4.7 \mathrm{mg} / \mathrm{L}$ for $\mathrm{NH}_{4}^{+}-\mathrm{N}, \mathrm{NO}_{2}^{-}-\mathrm{N}$ and $\mathrm{NO}_{3}^{-}-\mathrm{N}$, respectively. Considering the turbidity, the average values of $2.27 \pm 0.74$ and $2.04 \pm 0.8 \mathrm{NTU}$ were found in SBR A and SBR B, respectively.

In both cases, the adopted system allowed for the effective reduction of the monitored parameters. However, it should be mentioned that the reject water used in the present study was characterized by lower concentrations of most parameters than presented in the literature. Moreover, the relatively small contribution in the SBR inflow did not influence the process performance either. In the present study, the achieved removal efficiencies were comparable to the results presented in literature. In the full scale reactors involving the Anammox process, the $\mathrm{NH}_{4}{ }^{+} \mathrm{N}$ removal efficiencies exceeding $90 \%$ were reported [Hauck et al., 2016]. In the study performed by Podstawczyk et al. [2017] the membrane contactor system allowed for $98.9 \pm 0.1 \%$ reduction in the $\mathrm{NH}_{4}^{+}-\mathrm{N}$ concentration. However, in these cases the reactors were supplied only with the reject water.

Furthermore, there was no significant influence of the bioaugmentation strategy on the SBR performance operated at a decreased temperature. The exception was the phase with the lowest temperature; therein more favorable results for COD were obtained in the Archaea presence. In other cases, the decreased concentrations were found in the bioaugmented system; however, the differences between systems were of no statistical significance.

The different trend as obtained in the study presented by Cui et al. [2014]. In this case, the cold-adapted ammonia- and nitrite- oxidizing bacteria were applied for bioaugmentation to improve the nitrification efficiency in the sequencing batch reactors operated at low temperature. Therein, the beneficial effect of this strategy on the removal efficiencies was noted. The average removal efficiency of $\mathrm{NH}_{4}^{+}-\mathrm{N}$ in the bioaugmentation system was about $88 \%$, while in the nonbioaugmented system, it reached about $82 \%$. 
Considering COD reduction, it reached 83.8 and $85.8 \%$ in the bioaugmented and non-bioaugmented SBR, respectively. Another example of the implementation the bioaugmentation process in a reactor operating at low temperatures is the study performed by Figdore et al. [2018]. Therein, the NDN-PAO granules from sidestream centrate treatment were used for bioaugmentation. The authors concluded that bioaugmentation enhanced the nitrification process. In this case, the significant $\mathrm{NH}_{4}{ }^{+} \mathrm{N}$ removal efficiency of 95 $\pm 6 \%$ was observed. As in the present experiment, in the research conducted by Polus and Anielak [2017], the Archaea domain was used for the SBR bioaugmentation. In the presence of the bioaugmented product, the improved removal efficiency of nutrients was found. Therein, the total nitrogen reduction in bioaugmented reactor was $20 \%$ higher than in non-bioaugmented one. Though, it is worth noticing that many factors could diminish the effectives of bioaugmentation. The most important factors are: the strain used in system, dose of bioaugmented product, a sufficient acclimation time as well as process conditions such as flow treatment technology [Herrero and Stuckey, 2015]. Furthermore, in the present study, a short duration of individual phases might have contributed to obtaining minor differences between the bioaugmented and non- bioaugmented systems.

\section{CONCLUSIONS}

In the present study, the influence of bioaugmentation strategy on the co-treatment of reject water and municipal wastewater in SBR at a decreasing temperature was investigated. A mixture of wild-living bacteria and Archaea from Yellowstone National Park was used for bioaugmentation. The sudden temperature reduction did not adversely affect the process performance in the bioaugmented and non-bioaugmented systems. Significant removal efficiencies were achieved in both SBRs. Importantly, the major differences were observed for the COD parameter in the bioaugmented reactor at a temperature of $10^{\circ} \mathrm{C}$. In other cases, lower concentrations in the effluent were observed in the Archaea presence; however, the differences were of no statistical significance. Concluding, the adopted configuration of SBR allowed for an effective and profitable technology for reject water treatment.

\section{Acknowledgments}

The authors would like to thank Agnieszka Montusiewicz for providing the Archaea product (ArcheaSolutions Inc.).

\section{REFERENCES}

1. Babko R., Kuzmina T., Pliashechnik V., Łagód G. and Fyda, J. 2016. Anaerobic ciliates in activated sludge communities. Rocznik Ochrona Srodowiska, 18(2), 733-745.

2. Bathe S., Schwarzenbeck N. and Hausner M. 2019. Bioaugmentation of activated sludge towards 3-chloroaniline removal with a mixed bacterial population carrying a degradative plasmid. Bioresource Technology, 100, 2902-2909.

3. Benedetti B., Majone M., Cavaliere C., Montone C.M., Fatone F., Frison N., Laganà A, and Capriotti A.L. 2020. Determination of multi-class emerging contaminants in sludge and recovery materials from waste water treatment plants: Development of a modified QuEChERS method coupled to LC-MS/ MS. Microchemical Journal, 155, 104732.

4. Berends D.H.J.G., Salem S., van der Roest H.F. and van Loosdrecht M.C.M. 2005. Boosting nitrification with the BABE technology. Water Sci. Technol. 52, 63-70.

5. Boonnorat J., Techkarnjanaruk S., Honda R., Angthong S., Boonapatcharoen N., Muenmee S. and Prachanurak P. 2018. Use of aged sludge bioaugmentation in two-stage activated sludge system to enhance the biodegradation of toxic organic compounds in high strength wastewater. Chemosphere; 202, 208-217.

6. Cui D., Li A., Qiu T., Cai R., Pang Ch., Wang J., Yang J., Ma F. and Ren N. 2014. Improvement of nitrification efficiency by bioaugmentation in sequencing batch reactors at low temperature. Front. Environ. Sci. Eng. 8, 937-944.

7. Czarnota J., Masłoń A., Zdeb M. and Łagód G. 2020. The impact of different powdered mineral materials on selected properties of aerobic granular sludge. Molecules, 25(2), 386.

8. Deblonde T., Cossu-Leguille C. and Hartemann P. 2011. Emerging pollutants in wastewater: a review of the literature. International Journal of Hygiene and Environmental Health, 214 (6), 442-448.

9. Drewnowski J., Mąkinia J., Szaja A., Łagód G., KopećŁ. and Aguilar J.A. 2019. Comparative Study of Balancing SRT by Using Modified ASM2d in Control and Operation Strategy at Full-Scale WWTP. Water, 11, 485.

10. Drewnowski J., Remiszewska-Skwarek A., Duda, S. and Łagód, G. 2019. Aeration Process in Bioreactors 
as the Main Energy Consumer in a Wastewater Treatment Plant. Review of Solutions and Methods of Process Optimization. Processes, 7, 311.

11. Dudziak M. and Burdzik-Niemiec E. 2017. Ultrafiltration in the treatment of $17 \beta$-estradiol and bisphenol Acontaining wastewaters through modified membranes. Przemysl Chemiczny, 96(2), 448-452.

12. Figdore B.A., Stensel D.H. and Winkler M.K.H. 2018. Bioaugmentation of sidestream nitrifyingdenitrifying phosphorus accumulating granules in a low-SRT activated sludge system at low temperature. Water Research, 135, 241-250.

13. Fyda J., Babko R., Fiałkowska R., Pajdak-Stós A., Kocerba-Soroka W., Sobczyk M and Sobczyk Ł. 2015. Effect of high levels of the rotifer Lecane inermis on the ciliate community in laboratory-scale sequencing batch bioreactors (SBRs). European Journal of Protistology, 51(5), 470-479.

14. Gernaey K. and Sin G. 2008. Wastewater Treatment Models. In Jørgensen SE, Fath BD, editors, Encyclopedia of Ecology. Vol. 5: Ecological Models. Oxford Elsevier, 3705-3718.

15. Grabas M., Tomaszek J., Czerwieniec E., Masłoń A. and Łuczyszyn J. 2016. Application of a biopreparation with cultures of effective microorganisms to the processing of wastewater sludge on a semi-industrial scale. Environment Protection Engineering, 42 (1), 33-44.

16. Guo J., Wang J., Cui D., Wang L., Ma F., Chang C.C. and Yang J. 2010. Application of bioaugmentation in the rapid start-up and stable operation of biological processes for municipal wastewater treatment at low temperatures. Bioresource Technology, 101 (17), 6622-6629.

17. Guo X., Li Y., Zhong H., Li P., Zhao T. and Zhang C. 2019. A wastewater treatment system combining Myriophyllumaquaticum and activated sludge: Optimization of construction conditions and evaluation of wastewater treatment performance. Journal of Environmental Management, 235, 105-111.

18. Guz Ł., Łagód G., Jaromin-Gleń K., Suchorab Z., Sobczuk H. and Bieganowski A. 2015. Application of gas sensor arrays in assessment of wastewater purification effects. Sensors, 15, 1-21.

19. Hauck M., Maalcke-Luesken F. A, Jetten M. S.M. and Huijbregts M. A.J. 2016. Removing nitrogen from wastewater with side stream anammox: What are the trade-offs between environmental impacts? Resources, conservation, and recycling, 107, 212-219.

20. Head M.A. and Oleszkiewicz J.A. 2004. Bioaugmentation for nitrification at cold temperatures. Water Research, 38 (3), 523-530.

21. Herrero M. and Stuckey D. 2014. Bioaugmentation and its application in wastewater treatment: A review. Chemosphere, 140, 119-128.
22. Hu D., Zhen Z., Niu T., Wei Dou W., Weixiao \& Jiang L.M. and Lv Y. 2017. Co-treatment of reject water from sludge dewatering and supernatant from sludge lime stabilization process for nutrient removal: A cost-effective approach. Separation and Purification Technology, 172, 357-365.

23. Katsou E., Alvarino T., Malamis S., Suarez S., Frison N., Omil F. and Fatone, F. 2016. Effects of selected pharmaceuticals on nitrogen and phosphorus removal bioprocesses. Chemical Engineering Journal, 295, 509-517.

24. Kudlek E. and Dudziak M. 2018. The assessment of changes in the membrane surface during the filtration of wastewater treatment plant effluent. Desalination and Water Treatment, 128, 298-305.

25. Lebiocka M., Montusiewicz A. and Cydzik-Kwiatkowska A. 2018. Effect of bioaugmentation on biogas yields and kinetics in anaerobic digestion of sewage sludge. Int. J. Environ. Res. Public Health, 15(8), 1717.

26. Łagód G., Guz Ł., Sabba F. and Sobczuk H. 2018. Detection of wastewater treatment process disturbances in bioreactors using the e-nose technology. Ecological Chemistry and Engineering S, 25(3), 405-418.

27. Ma F., Guo J., Zhao L.J., Chang C.C., Cui D. 2009. Application of bioaugmentation to improve the activated sludge system into the contact oxidation system treating petrochemical wastewater. Bioresource Technology, 100 (2), 597-602.

28. Marttinen S.K., Ruissalo M. and Rintala J.A. 2004. Removal of bis (2-ethylhexyl) phthalate from reject water in a nitrogen-removing sequencing batch reactor. Journal of Environmental Management, 73 (2), 103-109.

29. Masłoń A. 2017. Analysis of energy consumption at the Rzeszów Wastewater Treatment Plant. E3S Web of Conferences, 22, 00115.

30. Park D., Lee D.S., Kim Y.M. and Park J.M. 2008. Bioaugmentation of cyanide-degrading microorganisms in a full-scale cokes wastewater treatment facility. Bioresource Technology, 99, 2092-2096.

31. Perez R., Gali A., Dosta J. and Mata-Alvarez J. 2007. Biological nitrogen removal singsulfides for autotrophic denitrification in a sequencing batch reactor to treat reject water. Ind. Eng. Chem. Res. 46, 6646-6649.

32. Piechna P. and Zubrowska-Sudoł M. 2017. Respirometric Activity of Activated Sludge and Biofilm in IFAS-MBBR System. J. Ecol. Eng. 2017, 18, 145-151.

33. Podstawczyk D., Witek-Krowiak A., DawiecLiśniewska A., Chrobot P. and Skrzypczak D. 2017. Removal of ammonium and orthophosphates from reject water generated during dewatering of digested sewage sludge in municipal wastewater treatment 
plant using adsorption and membrane contactor system. Journal of Cleaner Production, 161, 277-287.

34. Polus M. and Anielak A.M. 2017. The use of Archaea in the bioaugmentation of activated sludge as a method for the biological removal of nitrogen compounds. Technical Transactions, 5(114), 83-95.

35. Ren W., Zhou Z., Jiang L., Hu D., Qiu Z.H., Wei H. and Wang, L. 2015. A cost-effective method for the treatment of reject water from sludge dewatering process using supernatant from sludge lime stabilization. Separation and Purification Technology, 142, 123-128.

36. Roots P., Sabba F., Rosenthal A.F., Wang Y., Yuan O., Rieger L., Yang F., Kozak J.A., Zhang H. and Wells G.F. 2020. Integrated shortcut nitrogen and biological phosphorus removal from mainstream wastewater: Process operation and modeling. Environ. Sci., 6, 566-580.

37. Semrany, Favier S., Djelal L., Taha H., Taha S. and Favier L. 2012. Bioaugmentation: Possible solution in the treatment of Bio-Refractory Organic Compounds (Bio-ROCs). Biochemical Engineering Journal, 69,75-86.

38. Shahzad M., Khan S.J. and Paul P. 2015. Influence of Temperature on the Performance of a Full-Scale Activated Sludge Process Operated at Varying Solids Retention Times Whilst Treating Municipal Sewage. Water, 7, 855-867.

39. Szaja A., Łagód G., Jaromin-Glen K. and Montusiewicz A. 2018. The Effect of bioaugmentation with Archaea on the oxygen uptake rate in a sequencing batch reactor. Water, 10, 575.

40. Szeląg B., Barbusiński K. and Studziński J. 2018.
Activated sludge process modelling using selected machine learning techniques. Desalination and Water Treatment, 117, 78-87.

41. Tan W., Huang C., Chen Ch., Liang B. and Aijie W. 2016. Bioaugmentation of activated sludge with elemental sulfur producing strain Thiopseudomonas denitrificans X2 against nitrate shock load. Bioresource Technology, 220, 647-650.

42. Van Limbergen H., Top E. and Verstraete, W. 1988. Bioaugmentation in activated sludge: current features and future perspectives. Appl Microbiol Biotechnol, 50, 16-23.

43. Wang M., Yang G., Min H., Lv Z. and Jia, X. 2009. Bioaugmentation with the nicotine-degrading bacterium Pseudomonas sp. HF-1 in a sequencing batch reactor treating tobacco wastewater: degradation study and analysis of its mechanisms. Water Reserch, 43, 4187-4196.

44. Zhang T., Jin T., Yan Q., Shao M., Wells G., Criddle C. and Fang H.H. 2009. Occurrence of ammoniaoxidizing Archaea in activated sludges of a laboratory scale reactor and two wastewater treatment plants. Jounal of Applied Microbiology, 107(3), 970-977.

45. Zheng Y., Chai L.Y., Yang Z.H., Tang C.J., Chen Y.H. and Shi Y. 2013. Enhanced remediation of black liquor by activated sludge bioaugmented with a novel exogenous microorganism culture. Applied Microbiology and Biotechnology, 97, 6525-6535.

46. Zhou Y., Meng J., Zhang M., Chen S., He B., Zhao H., Li Q., Zhang S. and Wang T. 2019. Which type of pollutants need to be controlled with priority in wastewater treatment plants: Traditional or emerging pollutants? Environment International, 131, 104982. 